\title{
Déficit hídrico e a germinação de sementes de híbridos de milho
}

\author{
Ivanildo Guilherme HENRIQUE${ }^{1}$, Rafael Orlandini BOSQUEIRO'1, \\ Rafael Massaru KOTSUBO ${ }^{1}$, Silvia de Carvalho Campos BOTELHO² \\ ${ }^{1}$ Pós-Graduação em Agronomia, Universidade Federal de Mato Grosso, Sinop, MT, Brasil. \\ ${ }^{2}$ Embrapa Agrossilvipastoril, Sinop, MT, Brasil. \\ *E-mail: Ivanildo.guilhermee@gmail.com \\ (Orcid: 0000-0002-1585-3669; 0000-0001-5772-215X; 0000-0001-8943-9957; 0000-0002-2689-5303)
}

Recebido em 14/01/2020; Aceito em 24/06/2021; Publicado em 12/07/2021.

\begin{abstract}
RESUMO: Considerando a importância da água no processo de germinação de sementes, as condições adversas de umidade afetam diretamente o processo germinativo. Para tanto, objetivou-se avaliar a influência do deficit hídrico na germinação e vigor de sementes de dois genótipos comerciais de milho, induzido por diferentes potenciais osmóticos. Utilizou-se delineamento experimental inteiramente casualizados (DIC), arranjado em esquema fatorial duplo 2x5, com quatro repetições, avaliando híbridos de milho (DKB255PRO3 e DKB390PRO2), submetidos a germinação sob condições de déficit hídrico, em cinco níveis de potencial osmótico $(0,-0,6,-1,2,-1,8$ e -2,4 MPa). Cada unidade experimental constituiu-se por um rolo de papel germitest contendo 50 sementes. Utilizou-se $\mathrm{NaCl}$ como agente osmótico indutor de deficiência hídrica as sementes. Avaliou-se a germinação, vigor de sementes e o desenvolvimento inicial das plântulas, em termos de comprimento e biomassa. O déficit hídrico, simulado com solução de cloreto de sódio, provoca redução no desempenho de sementes de híbridos de milho. Os genótipos de milho respondem diferentemente quanto a tolerância a condições de estresse provocado por indisponibilidade de água durante a germinação. O híbrido DKB390PRO2 apresenta germinação e crescimento de plântulas superior quando submetido a diferentes níveis de potencial osmótico de $\mathrm{NaCl}$.
\end{abstract}

Palavras-chave: viabilidade de sementes; restrição hídrica; Zea mays.

\section{Effect of water deficit on the maize seed germination}

\begin{abstract}
Considering the importance of water in the seed germination process and knowing that conditions will not always be the most adequate to the germination process, the objective was to evaluate the influence of water deficit on germination and vigor in seeds of different commercial corn genotypes induced by different osmotic potentials. A completely randomized experimental design (D.I.C) was used, arranged in a $2 \times 5$ double factorial scheme, with four replications. Each experimental unit was constituted by a roll containing 50 seeds, made in germitest paper. Two maize seed hybrids (DKB255PRO3 and DKB390PRO2) were evaluated, submitted to germination under water deficit conditions, with levels $0 ;-0,6 .-1,2 ;-1,8$ and $-2,4 \mathrm{MPa}$ of osmotic potential. $\mathrm{NaCl}$ was used as osmotic agent inducing water deficiency in seeds. Germination, seed vigor and initial seedling development were evaluated in terms of length and biomass. The water deficit simulated with sodium chloride solution, causes a reduction in the performance of maize hybrids seeds. Corn genotypes respond differently to tolerance to stress conditions caused by unavailability of water during germination. The hybrid DKB390PRO2 presents superior germination and seedling growth when submitted to different levels of osmotic $\mathrm{NaCl}$ potential.
\end{abstract}

Keywords: viability; water restriction; Zea mays.

\section{INTRODUÇÃO}

O estresse hídrico é uma restrição ambiental severa à produtividade agrícola, atuando como fator determinante no cultivo das mais variadas espécies de interesse econômico. Indiscutivelmente a água tem importância fundamental nos mais diversos processos biológicos existentes, inclusive aqueles relacionados a produção vegetal. A disponibilidade hídrica e o movimento da água para as sementes são importantes para a germinação e emergência das plântulas, e desse modo, são fatores influenciados pelo potencial hídrico do solo (KAPPES et al., 2009).

Nem sempre o solo oferece um ambiente ótimo para a germinação das sementes e uma das condições por vezes encontrada é a pouca disponibilidade de água logo após a semeadura (Coelho et al., 2010). Nessa condição, o solo apresenta potenciais hídricos que dificultam a absorção da água necessária para a germinação das sementes (MACHADO NETO et al., 2006), o que configura o estresse hídrico logo após o plantio como um dos fatores abióticos que mais influência no processo germinativo, interferindo na atividade enzimática da planta (GARCIA et al., 2012).

Desse modo, potenciais hídricos muito negativos, especialmente no início da embebição, influenciam a absorção de água pelas sementes, podendo inviabilizar a sequência de eventos do processo germinativo (MIKUSINSKI, 1987).

Dadas essas circunstâncias e considerando a importância da água para a germinação de sementes a campo, compreender as respostas fisiológicas das plantas em função 
da variação de disponibilidade hídrica torna-se de extrema importância.

Assim, o objetivo deste trabalho foi simular condições de déficit hídrico, induzido por soluções de cloreto de sódio, e avaliar se a germinação e o vigor de sementes de genótipos comerciais de milho são influenciados pela menor disponibilidade de água.

\section{MATERIAL E MÉTODOS}

\subsection{Localização e Delineamento experimental}

O experimento foi conduzido no Laboratório de Sementes e Mudas da EMBRAPA - Empresa Brasileira de Pesquisa Agropecuária, unidade de Sinop/MT (Embrapa Agrossilvipastoril), entre os meses de maio e junho de 2019.

Foram avaliados dez tratamentos, resultantes da combinação entre dois genótipos de milho e cinco diferentes níveis de potencial osmótico aos quais estes materiais foram submetidos, utilizando para isso solução de cloreto de sódio. $\mathrm{O}$ delineamento experimental adotado para o ensaio foi o inteiramente casualizado (DIC), arranjado em esquema fatorial duplo $2 \times 5$ (genótipos de milho x níveis de potencial osmótico, respectivamente), em quatro repetições. Cada unidade experimental constituiu-se por um rolo de papel germitest contendo 50 sementes.

\subsection{Implantação e condução do experimento}

Foram utilizadas sementes comerciais dos híbridos de milho DKB255PRO3 e DKB390PRO2, padronizadas quanto ao tamanho e forma, para cada material, visando reduzir efeito do tamanho no vigor das sementes. As sementes foram submetidas à germinação sob condições de deficit hídrico, com os níveis 0 ; -0,6. -1,2; -1,8 e -2,4 MPa de potencial osmótico (Tabela 1$)$. Considerou-se o nível zero de potencial osmótico como testemunha, utilizando-se apenas água destilada para hidratação do substrato.

Tabela 1. Concentração de $\mathrm{NaCl}$ na solução e os respectivos níveis de potenciais osmóticos induzidos.

Table $1 . \mathrm{NaCl}$ concentration in the solution and its levels of induced osmotic potentials

\begin{tabular}{cc}
\hline $\begin{array}{c}\text { Níveis de Potencial } \\
\text { Osmótico }(\mathrm{MPa})\end{array}$ & $\mathrm{NaCl}\left(\mathrm{g} \mathrm{L}^{-1}\right)$ \\
\hline 0,0 & 0 \\
$-0,6$ & 8,40 \\
$-1,2$ & 16,80 \\
$-1,8$ & 25,20 \\
$-2,4$ & 33,60 \\
\hline
\end{tabular}

Para obtenção do potencial osmótico desejado, utilizouse soluções de cloreto de sódio $(\mathrm{NaCl})$, em diferentes concentrações (Tabela 01). Para o cálculo das concentrações, a fórmula de Van't Hoff foi utilizada, conforme a equação a seguir: Yos = - RTC, onde Yos: potencial osmótico (MPa); $\mathrm{R}$ : constante geral dos gases perfeitos $\left(0,082 \mathrm{Mpa} \mathrm{dm}^{-3} \mathrm{~mol}^{-1}\right.$ $\left.\mathrm{k}^{-1}\right)$; T: temperatura $\left({ }^{\circ} \mathrm{C}\right)$; e $\mathrm{C}$ : concentração $\left(\mathrm{mol} \mathrm{dm} \mathrm{dm}^{-3}\right)$ (SALISBURY; ROSS, 1991).

Cinquenta sementes de cada genótipo foram dispostas para germinar em folhas de papel (germitest), umedecidas com 2,5 vezes a sua massa, com soluções osmóticas de cloreto de sódio para proporcionar diferentes níveis de potencial osmótico. Inicialmente, as sementes foram alocadas sobre duas folhas e recobertas com uma terceira folha de papel, em seguida, enroladas e presas por uma liga de náilon, postas em sacos plásticos e alocadas em uma câmara de germinação (B.O.D.), com umidade de $92 \%$ e temperatura de $25^{\circ} \mathrm{C}$, permanecendo nesta condição por um período de sete dias.

\subsection{Variáveis analisadas}

A avaliação da primeira contagem de germinação foi realizada no quarto dia após a instalação do teste. A contagem final de germinação (segunda contagem), obtida pela somatória com a primeira contagem de germinação, foi realizada no sétimo dia após a instalação do teste (Brasil, 2009). Para a análise do teste de geminação, utilizou-se o critério de emissão de radícula, e para o desenvolvimento a medição da radícula e do coleóptilo das plântulas normais desenvolvidas. Posteriormente, os dados foram convertidos para porcentagem de plântulas normais (Brasil, 2009).

A velocidade de germinação foi calculada pela fórmula de Edmond e Drapala (1958): V.G. $=\left[\left(\mathrm{D}_{1} \times \mathrm{P}_{1}\right)+\left(\mathrm{D}_{2} \times \mathrm{P}_{2}\right)\right] /$ $\left(\mathrm{P}_{1}+\mathrm{P}_{2}\right)$, onde: $\mathrm{V} . \mathrm{G}$. é a velocidade de germinação, expressa em número de dias médios para a germinação; $\mathrm{D}_{1}$ e $\mathrm{D} 2$ correspondem aos números de dias da semeadura a primeira e segunda contagem, respectivamente; $\mathrm{P}_{1}$ e $\mathrm{P}_{2}$ correspondem aos números de plântulas normais na primeira e segunda contagem de germinação, respectivamente.

Assim, a primeira contagem e velocidade de germinação foram empregadas como indicativo do vigor e a contagem final, da viabilidade das sementes.

A avaliação do crescimento das plântulas foi realizada apenas nas plântulas normais, eliminando-se as anormais e as sementes mortas, por meio da medição do comprimento da raiz primária, comprimento da parte aérea e biomassa fresca de plântula. A avaliação foi realizada no sétimo dia após a instalação do teste, com auxílio de régua milimetrada, utilizando-se cinco plântulas aleatórias de cada unidade experimental e os resultados médios expressos em centímetros e gramas por plântula.

A determinação da biomassa fresca de plântula (raízes e parte aérea) foi realizada após a avaliação do comprimento da raiz e da parte aérea. Nesta avaliação, também se considerou as plântulas normais originadas nos respectivos tratamentos, as quais foram submetidas à pesagem em balança de precisão. A massa total obtida, em cada amostra, foi dividida pelo número de plântulas normais utilizadas, obtendo-se a biomassa fresca média de plântula (g plântula $\left.{ }^{-1}\right)$.

\subsection{Análise estatística dos dados}

Os dados foram submetidos à análise de variância, verificando-se a significância ao nível de $5 \%$ de probabilidade pelo teste F. Detectando-se diferenças significativas entre os tratamentos, as médias foram comparadas entre si pelo teste de Tukey, e, então, realizadas as análises de regressão para os diferentes potenciais osmóticos.

\section{RESULTADOS}

O resumo da análise de variância e valores médios observados para as variáveis mensuradas é apresentado na Tabela 2. Efeitos significativos $(P<0,05)$ foram observados para os híbridos de milho e níveis de potencial osmótico avaliados, assim como para a interação entre os fatores, na maioria das variáveis. Isso indica que os híbridos se comportaram de maneira distinta em relação ao nível de potencial osmótico, aos quais as sementes foram submetidas durante a germinação. 
Houve efeito significativo do estresse hídrico, induzido com a solução de $\mathrm{NaCl}$, sobre as variáveis analisadas, indicando influência de diferentes níveis de deficit hídrico sobre a germinação e vigor de sementes de milho. De maneira geral, o percentual de germinação na primeira contagem e aos 7 dias após instalação do ensaio, assim como crescimento e biomassa das plântulas (Tabela 2), apresentou redução da germinação em função da redução do potencial osmótico. No que se refere aos materiais genéticos avaliados, notou-se superioridade do híbrido DKB390PRO2, o qual apresentou maiores percentuais de germinação, acúmulo de biomassa e crescimento das plântulas. Este lote de sementes apresentou ainda menor número de plântulas anormais.

Tabela 2. Percentual de germinação na primeira contagem (PC), germinação (G), velocidade de germinação (VG), plântulas anormais (PA), comprimento da radícula (CR), comprimento do coleóptilo (CC), massa verde de raízes (MVR), massa verde do coleóptilo (MVC) de sementes de milho.

Table1. First count germination percentage (PC), germination $(\mathrm{G})$, germination speed (VG), abnormal seedlings (PA), root length (CR), coleoptile length (CC), green root mass (MVR), coleoptile green mass (MVC) of corn seeds.

\begin{tabular}{|c|c|c|c|c|c|c|c|c|}
\hline Tratamentos & PC $(\%)$ & $G(\%)$ & VG (dias) & PA $(\%)$ & $\mathrm{CR}(\mathrm{cm})$ & $\mathrm{CC}(\mathrm{cm})$ & MVR (g) & MVC (g) \\
\hline \multicolumn{9}{|l|}{ Híbrido (Fator A) } \\
\hline DKB255PRO3 & $52,90 \mathrm{~b}$ & $71,60 \mathrm{~b}$ & $5,99 \mathrm{~b}$ & $24,10 \mathrm{a}$ & $4,15 b$ & $3,71 b$ & $0,07 \mathrm{a}$ & $0,12 b$ \\
\hline DKB390PRO2 & $63,90 \mathrm{a}$ & $85,30 \mathrm{a}$ & $5,93 \mathrm{a}$ & $16,90 \mathrm{~b}$ & $5,81 \mathrm{a}$ & $4,81 \mathrm{a}$ & $0,08 \mathrm{a}$ & $0,14 \mathrm{a}$ \\
\hline $\mathrm{F}(\mathrm{A})$ & $46,1^{* *}$ & $73,8^{* *}$ & $4,9^{*}$ & $16,4^{* *}$ & $106,8^{* *}$ & $14,2^{* *}$ & $3,13^{\text {ns }}$ & $10,4^{*}$ \\
\hline $\operatorname{Pr}>\mathrm{Fc}$ & $<0,001$ & $<0,001$ & $<0,05$ & $<0,001$ & $<0,001$ & $<0,001$ & $<0,08$ & $<0,05$ \\
\hline dms & 3,323 & 3,271 & 0,048 & 3,643 & 0,329 & 0,601 & 0,007 & 0,012 \\
\hline \multicolumn{9}{|c|}{ Potencial osmótico (Fator B) } \\
\hline $0,0 \mathrm{MPa}$ & $95,75 a$ & $97,50 \mathrm{a}$ & $5,51 \mathrm{c}$ & $2,25 \mathrm{~d}$ & $15,33 a$ & $13,56 a$ & $0,17 \mathrm{a}$ & $0,44 a$ \\
\hline$-0,6 \mathrm{MPa}$ & $90,00 \mathrm{a}$ & $97,50 \mathrm{a}$ & $5,56 \mathrm{c}$ & $2,50 \mathrm{~d}$ & $5,64 \mathrm{~b}$ & $5,80 \mathrm{~b}$ & $0,13 b$ & $0,16 \mathrm{~b}$ \\
\hline$-1,2 \mathrm{MPa}$ & $74,75 \mathrm{~b}$ & $86,25 b$ & $5,61 \mathrm{c}$ & $16,00 \mathrm{c}$ & $2,56 \mathrm{c}$ & $1,50 \mathrm{c}$ & $0,05 c$ & $0,04 \mathrm{c}$ \\
\hline$-1,8 \mathrm{MPa}$ & $31,50 \mathrm{c}$ & $75,75 c$ & $6,12 \mathrm{~b}$ & $46,50 \mathrm{~b}$ & $1,05 d$ & $0,44 \mathrm{~cd}$ & $0,02 \mathrm{~d}$ & $0,01 \mathrm{~d}$ \\
\hline$-2,4 \mathrm{MPa}$ & $0,00 \mathrm{~d}$ & $35,25 \mathrm{~d}$ & $7,00 \mathrm{a}$ & $35,50 \mathrm{a}$ & $0,30 \mathrm{e}$ & $0,00 \mathrm{~d}$ & $0,01 \mathrm{~d}$ & $0,001 d$ \\
\hline $\mathrm{F}(\mathrm{B})$ & $517,9^{* *}$ & $209,3^{* *}$ & $571,7^{* *}$ & $99,6^{* *}$ & $1166^{* *}$ & $300,6^{* *}$ & $341,3^{* *}$ & $768,7^{* *}$ \\
\hline $\operatorname{Pr}>\mathrm{Fc}$ & $<0,001$ & $<0,001$ & $<0,001$ & $<0,001$ & $<0,001$ & $<0,001$ & $<0,001$ & $<0,001$ \\
\hline $\mathrm{dms}$ & 7,482 & 7,364 & 0,108 & 8,203 & 0,742 & 1,354 & 0,015 & 0,027 \\
\hline $\mathrm{F}(\mathrm{A} \times \mathrm{B})$ & $7,1^{*}$ & $12,2^{* *}$ & $0,6^{\mathrm{ns}}$ & $16,3^{* *}$ & $38,4^{* *}$ & $7,6^{*}$ & $15,4^{* *}$ & $24,7^{* *}$ \\
\hline $\operatorname{Pr}>\mathrm{Fc}$ & $<0,05$ & $<0,001$ & $<0,638$ & $<0,001$ & $<0,001$ & $<0,001$ & $<0,001$ & $<0,001$ \\
\hline CV (\%) & 8,77 & 6,43 & 1,25 & 27,4 & 10,20 & 21,75 & 13,48 & 14,23 \\
\hline
\end{tabular}

* $P<0.05$; ** $P<0.001$; ns não significativo pelo teste F. Médias seguidas de letra distintas na coluna diferem entre si pelo teste de Tukey $(P<0,05)$.CV = coeficiente de variação; dms = diferença mínima significativa.
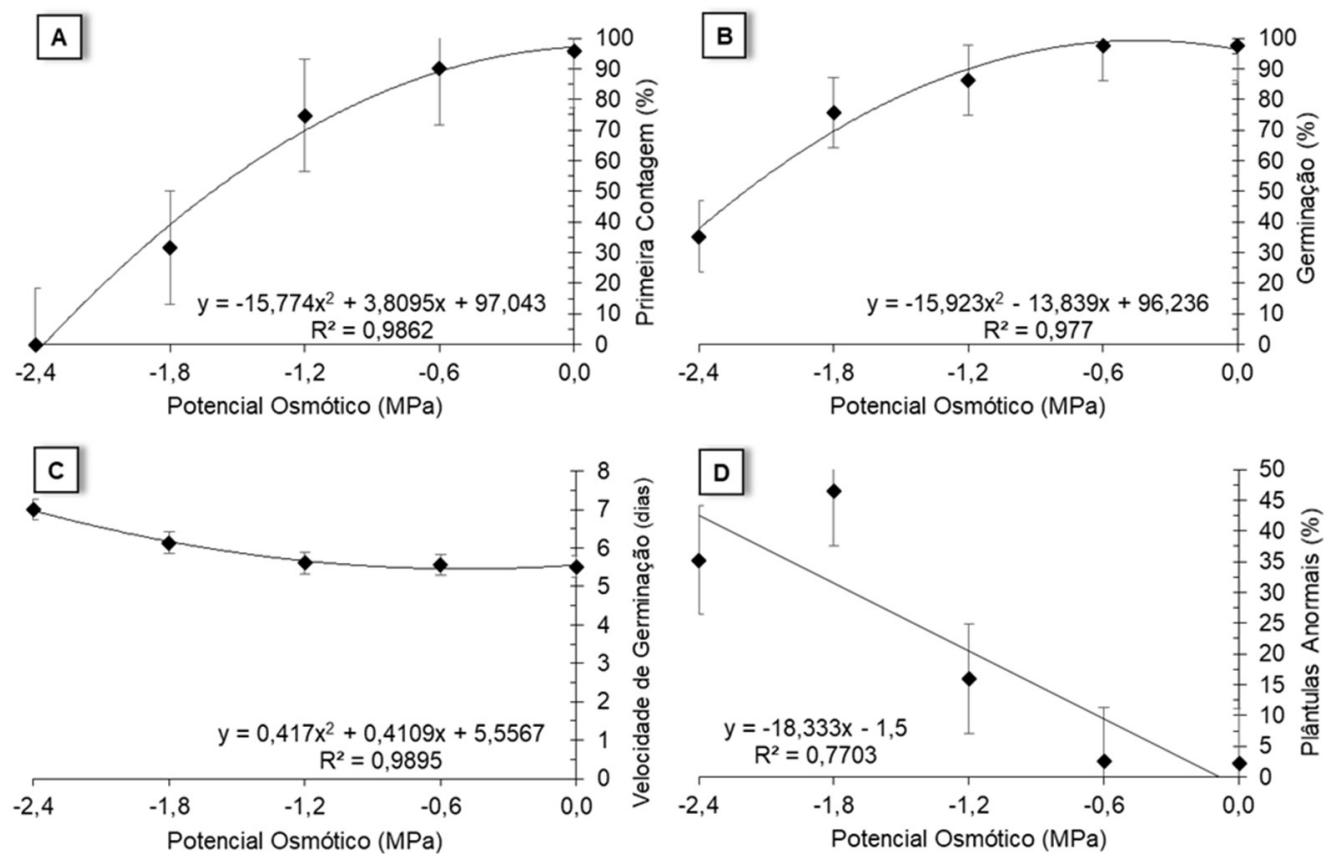

Figura 1. Primeira contagem (A), germinação (B), velocidade de germinação (C) e percentual de plântulas anormais (D), de sementes de milho sob a influência de diferentes níveis de potencial osmótico, em soluções de cloreto de sódio.

Figure 1. First count (A), germination (B), germination speed (C) and percentage of abnormal seedlings (D) of maize seeds under the influence of different osmotic potential levels in sodium chloride solutions. 
A velocidade de germinação também foi afetada pelos fatores avaliados nesse ensaio. O lote de sementes oriundo do híbrido DKB255PRO3 apresentou velocidade de germinação inferior, levando em média 5,99 dias para germinar após hidratação das sementes.

O potencial osmótico, obtido com solução de cloreto de sódio adicionado ao substrato de germinação, foi eficiente e proporcionou efeitos significativos sobre a germinação das sementes e desenvolvimento das plântulas. Verificou-se redução acentuada na velocidade de germinação, assim como no crescimento da radícula e da parte aérea das plântulas, de maneira que na maior concentração de sais pouco crescimento foi detectado nas sementes que emitiram radícula (Tabela 2 ).

A concentração da solução utilizada para umedecimento do substrato causou influência, ainda, no número de plântulas anormais observadas em cada tratamento. Verificou-se incremento no percentual médio de plântulas anormais em função da elevação na restrição hídrica a qual as sementes foram submetidas (Tabela 2).
$\mathrm{Na}$ análise de regressão (Figura 1, A e B), o modelo quadrático foi o que melhor se ajustou aos dados de primeira contagem de germinação e germinação final em função dos níveis de potencial osmótico. Observou-se decréscimo no vigor das sementes dos dois híbridos avaliados à medida que o potencial osmótico da solução foi diminuído. Constatou-se que a redução na disponibilidade de água contribuiu negativamente para o percentual e velocidade de germinação, assim como aumentou consideravelmente o número de plântulas anormais (Figura 1, C e D), apresentando para esta última variável, uma resposta linear em função do potencial osmótico.

A redução no potencial hídrico afetou negativamente o crescimento da parte aérea e raízes das plântulas, que demonstraram ter seu desenvolvimento prejudicado quando submetidos à ambientes com deficit hídrico (Figura 2, A e B). De maneira semelhante, a massa fresca da parte aérea e de raízes foi prejudicada pela imposição do deficit hídrico durante a germinação (Figura 2, C e D), inibindo completamente o desenvolvimento nos níveis de maior restrição.
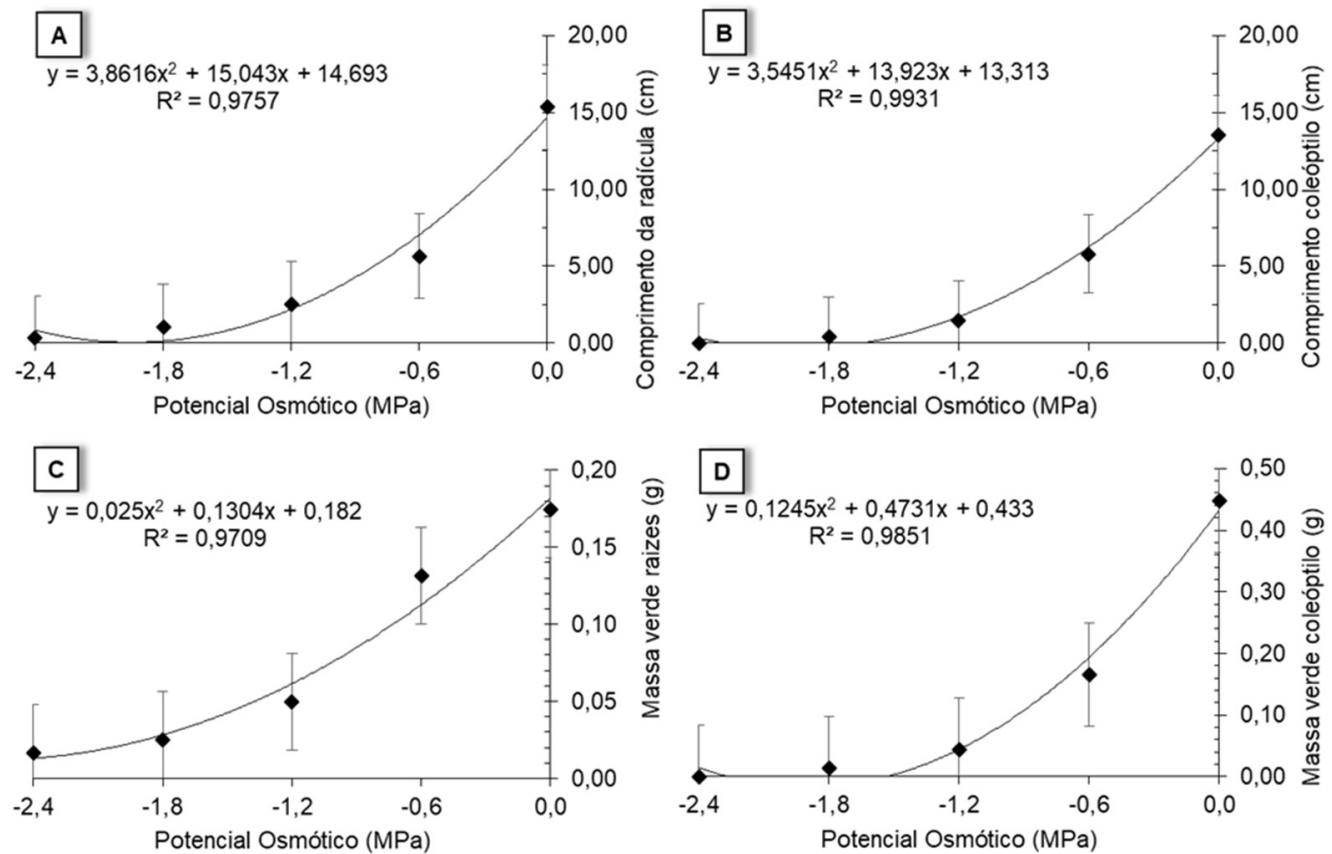

Figura 2. Comprimento da radícula (A), comprimento do coleóptilo (B), massa verde de raízes (C) e massa verde do coleóptilo (D), de sementes de milho sob a influência de diferentes níveis de potencial osmótico, em soluções de cloreto de sódio.

Figure 2. Root length (A), coleoptile length (B), root green mass (C) and coleoptile green mass (D) of maize seeds under the influence of different osmotic potential levels in solutions of sodium chloride.

Em relação ao comprimento da parte aérea (Figura 2B), as plântulas apresentaram os maiores valores no tratamento controle e no nível de potencial osmótico de -0,6 MPa de $\mathrm{NaCl}$. Nas concentrações mais elevadas $(-1,2,-1,8$ e $-2,4$ $\mathrm{MPa})$ não houve diferença no comprimento da parte aérea das plântulas entre os materiais de milho avaliados, sendo os valores apresentados nesses potenciais cerca de 14 vezes menores aos obtidos a $0,0 \mathrm{MPa}$.

As sementes do híbrido DKB390PRO2 apresentaram maior porcentagem de germinação e de plântulas normais na primeira contagem do teste de germinação, em praticamente todos os níveis de potencial osmótico de $\mathrm{NaCl}$ avaliados. Em comparação ao híbrido DKB255PRO3, exceto em 0,0 MPa, no qual não houve diferença significativa entre os materiais, e em -2,4 $\mathrm{MPa}$, onde o valor de porcentagem de plântulas normais foi zero para ambos materiais, na primeira contagem, nos demais níveis de potencial osmótico o material DKB390PRO2 mostrou-se mais tolerante a restrição hídrica na germinação (Figura 3, A).

Quanto ao número de plântulas normais, como já mencionado, este foi reduzido em função da restrição hídrica induzida, independente do híbrido de milho. Porém, verificou-se que os materiais genéticos responderam de maneira diferente a tais níveis de potencial osmótico. Em geral, o híbrido DKB255PRO3 foi mais prejudicado pela restrição hídrica na germinação, exceto a $0,0 \mathrm{MPa}$, no qual não houve diferença entre os dois materiais. 
Quanto à avaliação dos caracteres de crescimento, comprimento da parte aérea e de radícula das plântulas (Figura 4, A e B), os resultados foram condizentes com aqueles observados na porcentagem de germinação e na primeira contagem de germinação, em que as sementes do híbrido DKB390PRO2 apresentaram superioridade em relação ao DKB255PRO3, na maioria das diferentes concentrações do sal.
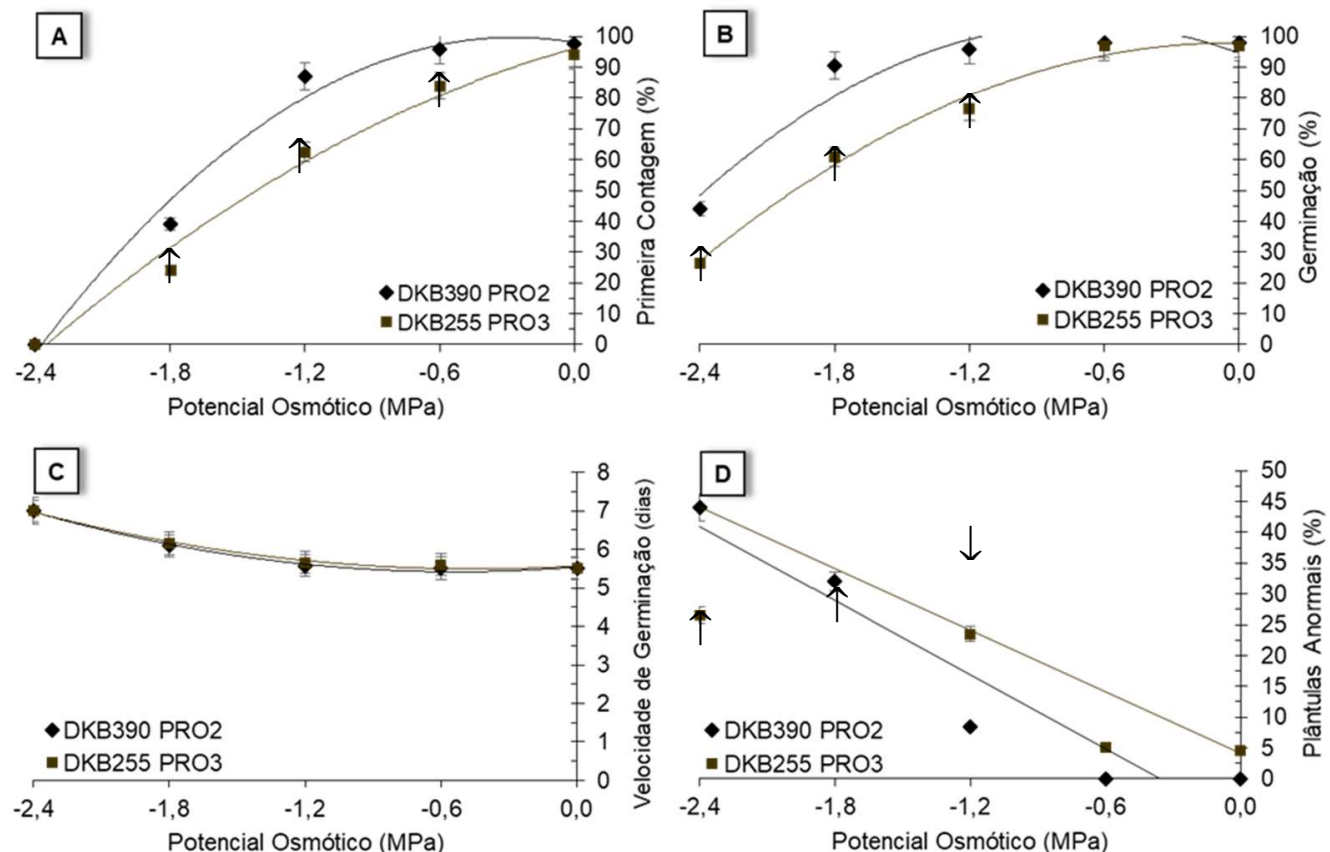

Figura 3. Desdobramento da interação genótipos de milho vs níveis de potencial osmótico para primeira contagem (A), germinação (B), velocidade de germinação (C) e percentual de plântulas anormais (D), de dois genótipos de milho (DKB390PRO2 e DKB255PRO3) em função de diferentes níveis de potencial osmótico. As setas indicam diferença significativa entre os genótipos pelo teste Tukey, a 5\% de probabilidade.

Figure 3. First count (A), germination (B), germination speed (C) and percentage of abnormal seedlings (D) of two maize genotypes (DKB390PRO2 and DKB255PRO3) as a function of different levels of osmotic potential. Arrows indicate significant difference between genotypes by Tukey test at $5 \%$ probability.
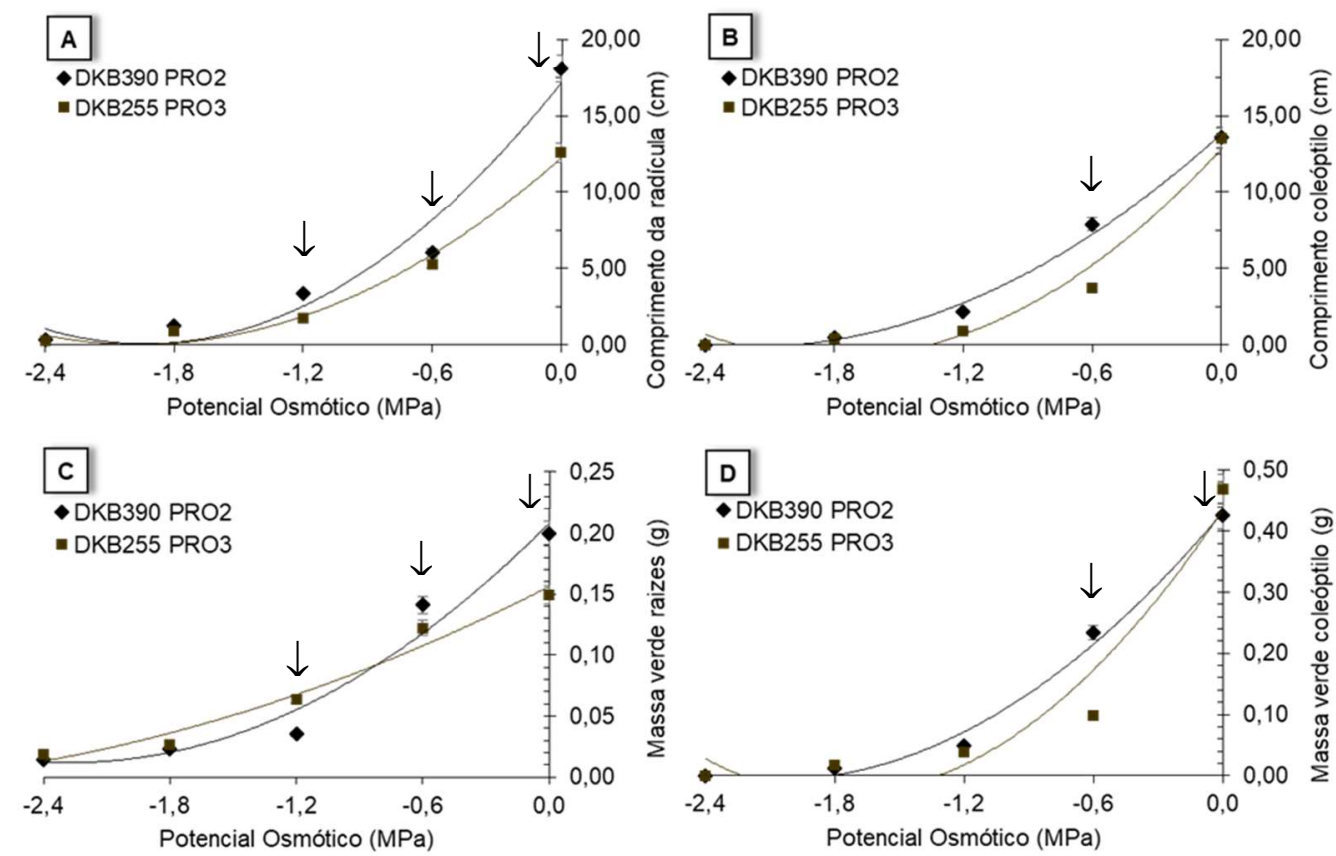

Figura 4. Comprimento da radícula (A), comprimento do coleóptilo (B), massa verde de raízes (C) e massa verde do coleóptilo (D), de dois genótipos de milho (DKB390PRO2 e DKB255PRO3) em função de diferentes níveis de potencial osmótico. As setas indicam diferença significativa entre os genótipos pelo teste Tukey, a $5 \%$ de probabilidade.

Figure 4. Root length (A), Coleoptera length (B), Root green mass (C) and Coleoptera green mass (D) of two maize genotypes (DKB390PRO2 and DKB255PRO3) as a function of different potential levels osmotic. Arrows indicate significant difference between genotypes by Tukey test at $5 \%$ probability. 

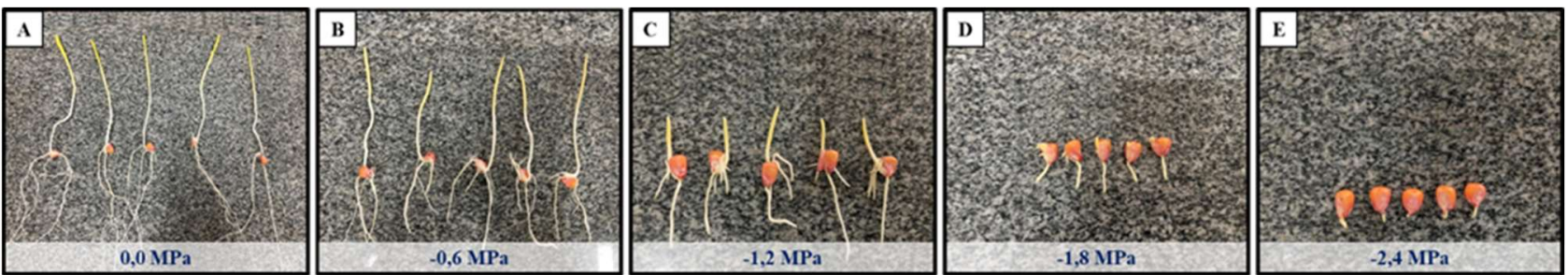

Figura 5. Desenvolvimento inicial de plântulas de milho (DKB390PRO2), em função de diferentes níveis de potencial osmótico. Figure 5. Initial development of corn seedlings (DKB390PRO2) as a function of different osmotic potential levels.

No que se refere a biomassa fresca do coleóptilo, também se verificou resultados superiores para o híbrido DKB390PRO2, nos tratamentos com potencial osmótico de 0,0 e $-0,6 \mathrm{MPa}$, sendo as respostas nos demais tratamentos estatisticamente semelhantes e inferiores (Figura 4D). Grande variabilidade nos resultados foi observada entre as sementes dos diferentes híbridos com a redução no potencial osmótico da solução para a massa verde de raízes. Entretanto, com potencial osmótico de $0,0 \mathrm{MPa}$, maior biomassa de raízes foi constatada nas plântulas provenientes do lote de sementes do híbrido DKB390PRO2 (Figura 4C).

\section{DISCUSSÃO}

Assim como verificado no presente estudo, Moterle et al. (2006) e Kappes et al. (2010) avaliando germinação de sementes e crescimento de plântulas de milho sob estresse hídrico simulado, verificaram interação significativa entre diferentes materiais genéticos e níveis de potencial osmótico para germinação, primeira contagem de germinação, comprimento da raiz primária e parte aérea de plântula.

A redução no potencial hídrico afetou negativamente todos os parâmetros avaliados durante a germinação das sementes de milho. Foi constatada redução no crescimento das raízes e parte aérea das plântulas, assim como observado por Viçosi et al. (2017), demonstrando que o desenvolvimento das plântulas de milho é prejudicado quando submetidas à ambientes em deficit hídrico. De maneira semelhante, a germinação e velocidade de germinação também foram afetadas negativamente.

Isso indica o efeito negativo do estresse hídrico e salino sobre o desenvolvimento inicial das plântulas. Resultados semelhantes também foram relatados por Tonin et al. (2000), com sementes de milho, sob concentrações de Polietileno Glicol.

O movimento e a disponibilidade de água para as sementes são de grande importância para a germinação, crescimento inicial do sistema radicular e emergência das plântulas (ÁVILA et al., 2007). Desse modo, a diminuição da germinação de sementes submetidas a estresse hídrico é atribuída à redução da atividade enzimática, resultando em menor desenvolvimento meristemático (POPINIGIS, 1985).

Confirmando tal afirmação, Soares et al. (2015) concluíram que a germinação das sementes pode ser severamente afetada pela baixa disponibilidade de água e consequente baixo potencial hídrico, principalmente em solos que exibem maiores teores de sais. Nesse sentido, potenciais hídricos muito negativos, especialmente no início da embebição, influenciam a absorção de água pelas sementes, podendo inviabilizar a sequência de eventos do processo germinativo (MIKUSINSKI, 1987).
Desse modo, o decréscimo no vigor das sementes dos híbridos avaliados com a redução no potencial osmótico da solução, segundo Bruni; Leopold (1992), pode ser atribuído pelo deficit de água durante a germinação, o que provoca a perda progressiva da turgescência protoplasmática e um aumento na concentração de solutos. Complementarmente, Larcher (1986) relatou que o excesso de íons no solo, como o $\mathrm{Cl}^{-}$, tende a causar intumescência protoplasmática, afetando a atividade enzimática e resultando na produção inadequada de energia e distúrbios na assimilação de nitrogênio. Essa afirmativa pode explicar os resultados encontrados no presente estudo em relação ao decréscimo da germinação das sementes.

A redução na germinação de sementes, com o aumento das concentrações de cloreto de sódio, pode ser atribuída ainda, como indicam Kappes et al. (2010) e Pelegrini et al. (2013), à redução da velocidade e quantidade de água absorvida pelas sementes, uma vez que o deficit hídrico durante a germinação inibe a absorção de água pelos tecidos, dificultando assim o início da germinação das sementes.

Respostas diferentes foram observadas entre os materiais genéticos avaliados, no que se refere à germinação e desenvolvimento de plântulas sob condições de restrição hídrica, imposta por redução no potencial osmótico da solução. Tal fato indica que a germinação de sementes de milho em condições de campo, nestes respectivos potenciais osmóticos torna-se, segundo Kappes et al. (2010), dependente do material genético (híbrido de milho), ou seja, o fator genótipo será determinante quanto à tolerância ou não ao deficit hídrico presente no solo. Vale ressaltar que outros fatores também podem atuar de forma conjunta ao deficit hídrico, potencializando os danos e interferindo no processo germinativo das sementes, como a temperatura do solo e do ar.

Embora tenha ocorrido redução na porcentagem de plântulas normais dos dois híbridos avaliados nos potenciais de -1,8 e -2,4 MPa, as sementes do híbrido DKB390PRO2 apresentaram maior capacidade germinativa (44\%) a $-2,4$ $\mathrm{MPa}$ de potencial osmótico, indicando menor interferência na viabilidade das sementes e maior capacidade de superar condições restritas de disponibilidade de água. De acordo com Ávila et al. (2007), o estresse hídrico contribui para a diminuição da velocidade e percentagem de germinação das sementes, sendo que para cada espécie existe um valor de potencial hídrico no solo, abaixo do qual a germinação não ocorre.

O número de sementes mortas, ou que não apresentaram emissão de radícula (dados não apresentados), sofreu incremento com a redução do potencial osmótico ao qual as sementes formam submetidas. Do mesmo modo, Santos et al. (1992) observaram que a porcentagem de sementes não 
germinadas, nos tratamentos sob condições de estresse salino, foi muito elevada nos menores valores de potenciais osmóticos, sugerindo que os efeitos tóxicos dos sais provocaram inibição da germinação.

\section{CONCLUSÕES}

O déficit hídrico, simulado com solução de cloreto de sódio, provoca redução no desempenho de sementes de híbridos de milho.

A redução no potencial osmótico do substrato promove redução significativa na germinação e vigor das sementes, assim como no crescimento das plântulas de milho.

Os genótipos de milho respondem diferentemente quanto à tolerância a condições de estresse provocado por indisponibilidade de água durante a germinação.

O híbrido DKB390PRO2 apresenta germinação e crescimento de plântulas superior quando submetido a diferentes níveis de potencial osmótico de $\mathrm{NaCl}$.

\section{AGRADECIMENTOS}

Os autores agradecem a EMBRAPA - Empresa Brasileira de Pesquisa Agropecuária, unidade de Sinop/MT (Embrapa Agrossilvipastoril), pelos recursos disponibilizados e ambiente laboratorial para o desenvolvimento da pesquisa.

\section{REFERÊNCIAS}

ÁVILA, M. R.; BRACCINI, A. D. L.; SCAPIM, C. A.; FAGLIARI, J. R.; SANTOS, J. D. Influência do estresse hídrico simulado com manitol na germinação de sementes e crescimento de plântulas de canola. Revista Brasileira de Sementes, Londrina, v. 29, n. 1, p. 98-106, 2007. DOI: http://dx.doi.org/10.1590/S010131222007000100014

BRASIL. Ministério da Agricultura, Pecuária e Abastecimento. Regras para análise de sementes. Ministério da Agricultura, Pecuária e Abastecimento. Secretaria de Defesa Agropecuária. Brasília: MAPA/ACS, 2009. 395p.

BRUNI, F.; LEOPOLD, A. C. Cytoplasmic glass formation in maize embryos. Seed Science Research, Wallingford, v. 2, n. 4, p. 251-253, 1992. DOI: https://doi.org/10.1017/S096 0258500001446

COELHO, D. L. M.; AGOSTINI, E. A. T.; GUABERTO, L. M.; NETO, N. B. M.; CUSTÓDIO, C. C. Estresse hídrico com diferentes osmóticos em sementes de feijão e expressão diferencial de proteínas durante a germinação. Acta Scientiarum. Agronomy, Maringá, v. 32, n. 3, p. 491-499, 2010. DOI: http://dx.doi.org/10.4025/ actasciagron.v32i3.4694

EDMOND, J. B.; DRAPALA, W. J. The effects of temperature, sand and soil, and acetone on germination of okra seeds. Proceedings of American Society of Horticultural Science, v. 71, n. 2, p. 428-434, 1958.
GARCIA, S. H.; ROZZETTO, D. S.; COIMBRA, J. L. M.; GUIDOLIN, A. F. Simulação de estresse hídrico em feijão pela diminuição do potencial osmótico. Revista de Ciências Agroveterinárias, Lages, v. 11, n. 1, p. 35-41, 2012.

KAPPES, C.; da COSTA ANDRADE, J. A.; HAGA, K. I.; FERREIRA, J. P.; ARF, M. V. Germinação, vigor de sementes e crescimento de plântulas de milho sob condições de déficit hídrico. Scientia Agraria, Curitiba, v. 11 , n. 2 , p. 125-134, 2009. DOI: http://dx.doi.org/10.5380/ rsa.v11i2.16464

LARCHER, W. Ecofisiologia vegetal. São Paulo: EPU, 1986. 319p.

MACHADO NETO, N. B.; CUSTÓDIO, C. C.; COSTA, P. R.; DONÁ, F. L. Deficiência hídrica induzida por diferentes agentes osmóticos na germinação e vigor de sementes de feijão. Revista Brasileira de Sementes, Londrina, v. 28, n. 1, p. 142-148, 2006. DOI: http://dx.doi.org/10.1590/ S0101-31222006000100020

MIKUSINSKI, O. M. Testes de embebição e germinação em sementes de Ipomoea aristolochiaefolia. Revista Brasileira de Sementes, Londrina, v. 9, n. 3, p. 103-108, 1987. DOI: 3122/rbs.v9n3p103-108

MOTERLE, L. M.; LOPES, P. D. C.; BRACCINI, A. D. L.; SCAPIM, C. A. Germinação de sementes e crescimento de plântulas de cultivares de milho-pipoca submetidas ao estresse hídrico e salino. Revista Brasileira de Sementes, Londrina, v. 28, n. 3, p. 169-176, 2006. DOI: http://dx.doi.org/10.1590/S0101-31222006000300024

PELEGRINI, L. L.; BORCIONI, E.; NOGUEIRA, A. C.; KOEHLER, H. S.; QUOIRIN, M. G. G. Efeito do estresse hídrico simulado com $\mathrm{NaCl}$, manitol e PEG (6000) na germinação de sementes de Erythrina falcata Benth. Ciência Florestal, Santa Maria, v. 23, n. 2, p. 511519, 2013.2 DOI: http://dx.doi.org/10.5902/198050989295

POPINIGIS, F. Fisiologia da semente. Brasília: AGIPLAN, 1985. 289p.

SALISBURY, F. B.; ROSS, C. W. Plant physiology. 4th ed. Belmont: Wadworth, 1991.

SOARES, M. M.; SANTOS JUNIOR, H. C. dos; SIMÕES, M. G.; PAZZIN, D.; SILVA, L. J. da. Estresse hídrico e salino em sementes de soja classificadas em diferentes tamanhos. Pesquisa Agropecuária Tropical, Goiânia, p. 370-378, 2015.2 DOI: http:/ /dx.doi.org/10.1590/1983-40632015v4535357

TONIN, G. A.; CARVALHO, N. M.; KRONKA, S. N.; FERRAUDO, A. S. Influência do cultivar e do vigor no desempenho germinativo de sementes de milho em condições de estresse hídrico. Revista Brasileira de Sementes, Londrina, v. 22, n. 1, p. 276-279, 2000.

VIÇOSI, K. A.; FERREIRA, A. A. S.; OLIVEIRA, L. A. B. de; RODRIGUES, F. Estresse hídrico simulado em genótipos de feijão, milho e soja. Revista de Agricultura Neotropical, Cassilândia, v. 4, n. 5, p. 36-42, 2017. 